\title{
Design and Research of the Interactive Teaching Platform Smart Classroom of Advanced Mathematics Course Based on the "Internet +"
}

\author{
Liyan Chen ${ }^{1,2}$, Hailiang Zhang ${ }^{1}$, Jinliang Cao ${ }^{1}$, \\ Jifeng Bao ${ }^{1}$ \\ ${ }^{1 .}$ Department of Mathematics, Physics and Information \\ Science \\ Zhejiang Ocean University \\ Zhoushan, China \\ chenliyan@tongji.edu.cn
}

\author{
Samuel Cheng* \\ 2. Department College of Electronics and Information \\ Engineering \\ Tongji University \\ Shanghai, China \\ samuel.cheng@ou.edu
}

\begin{abstract}
The rapid development of "Internet +" technology has promoted the modernization process of education. The advanced mathematics course is an essential basic course of a university. Its teaching model has direct influence on the teaching efficiency and teaching quality. Combined with the Wechat platform and PC software, with the use of "internet + education", the paper takes the "advanced mathematics" course for example to build an interactive teaching platform of Smart Classroom. Practice has proved that the teaching platform promotes the reform of teaching model of "advanced mathematics", increases the learning enthusiasm and initiative of students, and provides a new way for promoting the modernization of education and personalized education.
\end{abstract}

Keywords-Internet+; Advanced Mathematics; Wechat; Smart Classroom; Interactive Teaching

\section{INTRODUCTION}

Advanced mathematics is an essential basic discipline of the a university, which is not only an accurate scientific language used by various disciplines, but also plays an irreplaceable role in the study of subsequent courses and cultivation of students' thinking quality [1].

"Internet +education" uses the Internet technology and Internet thinking to achieve the integration of Internet and traditional education, to update the educational concept, reestablish the teaching mode, and improve teaching efficiency and teaching quality [2].

The concept of "Smart Classroom" was born under this context. As shown in Fig.1, "Smart Classroom " is interactionoriented, which provides effective support to the decisions of education through effective integration of the humanized, intellectual and informational teaching environment of a variety of technological means, which will become a development trend in the future smart education $[3,4]$.

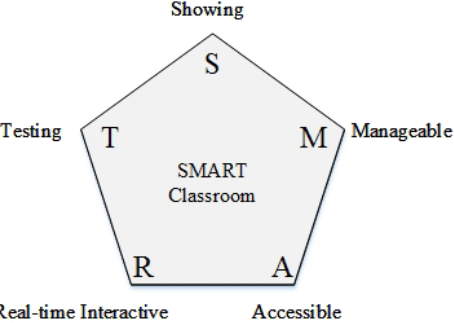

Fig. 1. The Model of the Smart Classroom

At present, the "advanced mathematics" of colleges and universities mainly adopts the traditional "transmissionacceptance" teaching model proposed by Herbart in the 19th century, which restricts the development of students' personality and creative ability. In order to improve the teaching efficiency and teaching quality by changing the "receptive" teaching model into "active" and "interactive" teaching mode, this paper constructs the interactive teaching mode of Smart Classroom with the use of the advanced technology of "Internet + ". The study of the subject contains the following research significance.

- Good interaction between teachers and students. Students can communicate with teachers at anytime and anywhere and teachers can also provide timely assistance to students.

- Good collaboration between students. Students can make online and offline learning and discussion through the teaching platform to facilitate collaborative learning among students.

- Records of learning behavior. Through the big data module, the system records, collects and analyzes the learning data, so that teachers can know about the learning dynamics of students in time to realize the modeling of learning behavior and personalized evaluation.

In conclusion, the interactive teaching model Smart Classroom of "advanced mathematics" course based on "Internet + " (ITSCI +$)$, breaks the traditional teacher-oriented 
teaching model, which meets the personalized demands of students in accordance with their aptitude, and also increases the learning efficiency, thus promoting the innovation of the integration between information technology and education.

In recent years, there has been a surge of research on new teaching models which based on the "Internet + " both at home and abroad. Sang Lei[5] discussed the status and relationship between teachers and students in the teaching community under the "Internet +" environment. Chen Yiming[6] analyzed the characteristics of "Internet +Education", then explored the modular teaching model which combined with the smart classroom of Higher Education law. JiangChong[7] explored the basic features of the smart classroom, and put forward the University smart classroom with the accurate and synchronous teaching contents, good interactive classroom environment, efficient record. Zhao Zhigang[8] studies the practice of online intelligent teaching in CISCO, Baidu cloud classrooms and Blackboard systems.

In addition, Massachusetts Institute of Technology, Harvard University, Stanford University and other top schools have launched the online open source education project platform based on the "Internet + "[9][10].

The rest of the paper is organized as follows: Section 2 presents the overall design and the basic framework of ITSCI+; Section 3 discusses the implementation principles and main function of the system.

\section{BASIC FRAMEWORK OF THE PLATFORM}

\section{A. Overall Design}

As show in Fig.2, ITSCI+ changes the traditional teaching model of "transmission-acceptance", extended the classroom learning beyond the classroom, increased interaction and communication of "teacher-student" and "student-student", at the same time it uses of a large number of network resources, big data analysis and WeChat platform to help teaching and learning. On the one hand, it makes the core knowledge of teaching resources easier to study and understand; on the other hand, the teaching and learning process become more efficient and interactive[11][12].

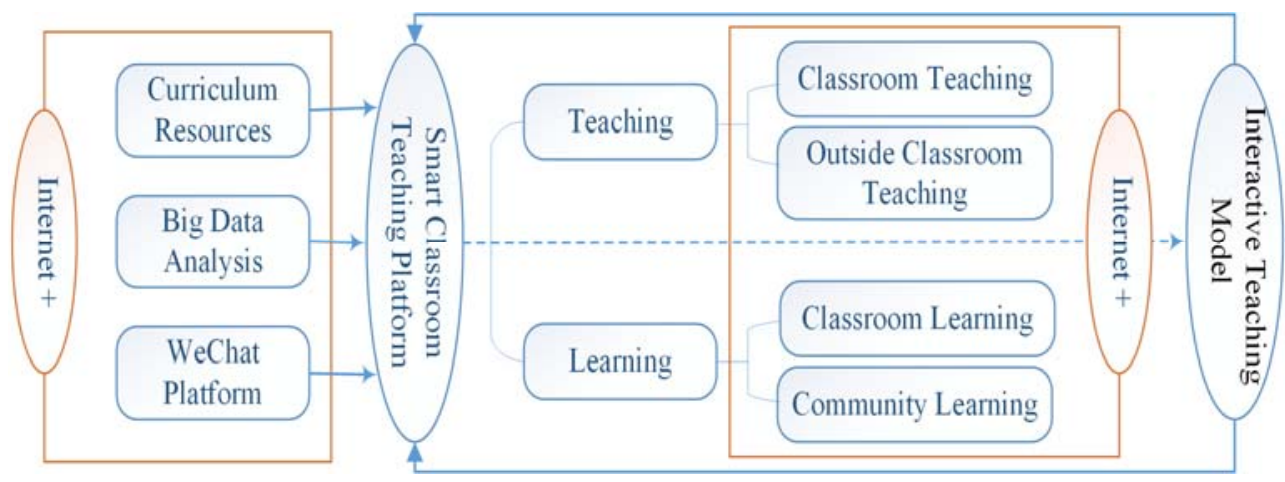

Fig. 2. Overall Design of the Platform

\section{B. System Framework}

As show in Fig.3, the smart classroom teaching platform includes two modules: teacher client and student client. The teacher client is a self-developed PC software, and the student client is based on the WeChat public platform interface. The main functions include call the roll in class, homework assignment, online test, resource sharing.

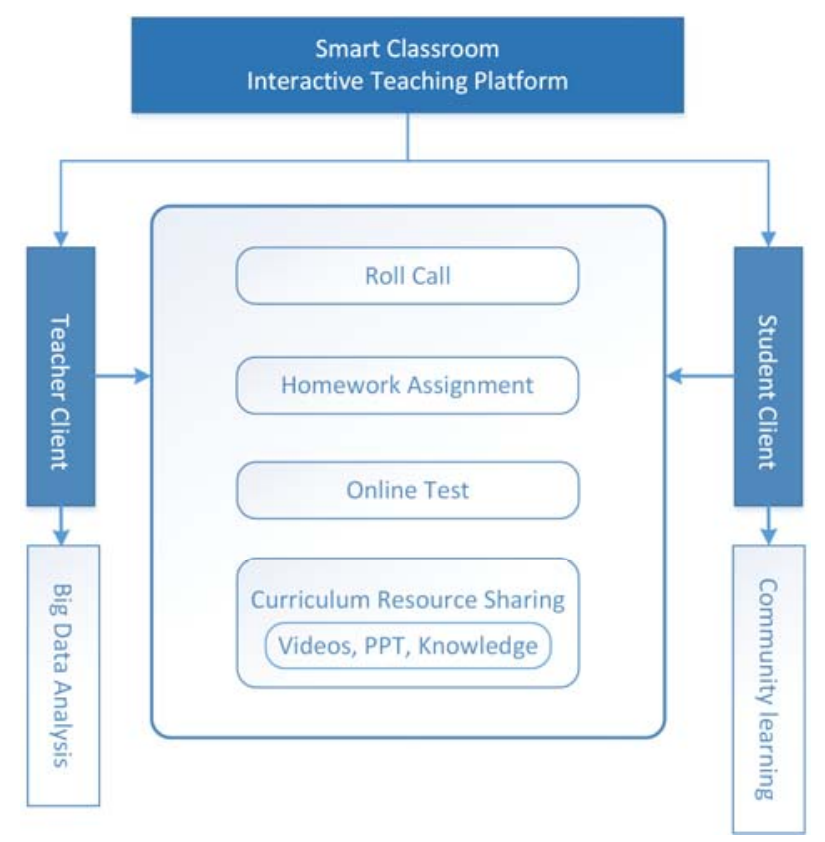

Fig. 3. The System Framework of the Platform 


\section{SYSTEM IMPLEMENTATION}

\section{A. Teacher-client development}

Teacher-client was developed taking advantage of $\mathrm{C}+$ Win32Api and $\mathrm{VC}++6.0$, using MySQL database. In order to facilitate dada sharing Teacher-client and student-client share the same database.

\section{1) Basic Principle}

As show in Fig. 4, when an operator controls an input device (such as a keyboard or mouse), the operation system can perceive changes in the state of the input device, then notifies the output device to perform specific functions.

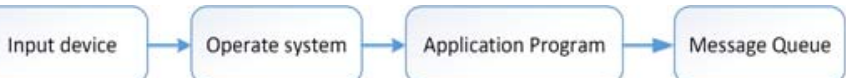

Fig. 4. The Basic Principle of the Teacher-client

\section{2) Functional Realization}

- Roll call module based on WeChat platform.

This function belongs to the initiative in the existing smart teaching platform. In class, as long as the teacher clicks the call button, the system will generate random verification code that is displayed on the screen, and stored in the database. Students can easily complete the call by typing this verification code at the mobile terminal. With this platform, teachers can achieve roll call work on hundreds of students within a few seconds; it saves time and improves efficiency.

- Curriculum resource sharing module.

Teachers can send teaching videos, teaching PPT and knowledge points to the student-client platform according to the course progress. Students can access the content on the WeChat public platform, including text, graphics and voice replies. So students can make full use of the fragmented time to study autonomously and effectively improve their learning efficiency.

- Online test module.

Teachers can use this module for automatic test paper generation. After the students finish the test, the system will automatically check the answers, and uses big data analysis of the system to test and analyze the results. Teachers can dynamically adjust the following teaching progress and teaching difficulty according to the statistical results, so as to realize individualized teaching and teach students in accordance with their aptitude.

\section{B. Student-client development}

The student-client is a WeChat public platform which exploits the interface provided by WeChat. It builds a Linux system under Ali cloud server, and applies Apache to construct Web server, use PHP programming language as development language, and MySQL is employed as the data storage system.

\section{1) Basic principle}

The student-client based on WeChat public platform adopts the response mode. Students can operate the system through
WeChat or send all kind of messages (including text, pictures, sound, video, position) to the system, the information will be transmitted to the WeChat server; then the server will look up the corresponding data in the database and POST a XML data; finally return to the WeChat pubic platform.

\section{2) Functional realization}

The student- client has added a community learning module in addition to roll call module, curriculum resource sharing module and online test module. In the community of learning module students can choose classmates of similar purpose and interests to build a learning community. They can conduct online discussion and communication, and the questions they don't understand can be sent to the discussion area in time, teachers and other students will help to solve the problem quickly. It improves the students' interest and initiative in learning, and increases the interaction and interaction between students and classmates, students and teachers.

\section{BRIEF SUMMARY}

The interactive teaching platform of Smart Classroom based on the "Internet +" has been promoted and used in "advanced mathematics". The mutual integration of online and offline learning makes the interactive learning between teachers and students, and students and students reach out of the classroom, which fully mobilizes the initiative of learners, and improves the learning interest and learning quality of students effectively. Due to strong compatibility, this platform can be extended to other courses.

\section{ACKNOWLEDGMENT}

This research is supported by Virtual Reality and Human Computer Interaction Laboratory of Tongji University and Education Technology Research Project of Zhejiang (JB024).

\section{REFERENCES}

[1] Gao Jie, Zhou Wei, "Exloration and Research of Developing Experiment Teaching in Higher Mathematics Course," Journal of Mathematics Education, vol. 24, pp. 86-90, March 2015.(In Chinese)

[2] Zhang Jiefu, "Five Great Revolutionary Influences Come From Internet +," People's Education, vol. 13, pp. 72-75, 2015.(In Chinese)

[3] Dong Zhongfang, "Design and Application of Interactive Classromm Teaching Based on Cloud Intelligent Classroom[D]", South China Normal University, GuangDong, 2014.(In Chinese)

[4] Zhong Xiaoliu, Song Shuqiang, Hu Min, Yang Xiaomin, Li Haixia, "Ecological Construction of Smart Education in the Fourth Educational Revolution," Distance Education Journal, pp. 34-40, April 2015.(In Chinese)

[5] Sang Lei, "The Evolution and Reconstruction of Teaching Community Based on Internet +," Higher Education Exploration, pp. 79-92, March 2016.(In Chinese)

[6] Chen Yiming, "On Teaching Environment and Teaching Mode Based on Internet +," Journal of Southwest China Normal University (Natural Science Edition), vol. 41, pp. 228-232, March 2016.(In Chinese)

[7] Jiang Chong, Fei Hongxiao, Ling Ruixuan, "Research on University smart Classroom Based on the Mobile Internet," The Chinese Journal of ICT in Education, pp.74-76, Janurary 2016.(In Chinese)

[8] Zhao Zhigang, Zhao Zhifang, "Study on the Reform of Wisdom Education to Promote the Innovation of Teaching," Computer\&Telecommunication, pp. 20-21, March 2016.(In Chinese) 
[9] Y. Shi, W. Xie, G. Xu, R. Shi, E. Chen, Y. Mao, "The Smart Classroom: Merging Technologies for Seamless Tele-education", IEEE Pervasive Computing, vol. 2, pp. 47-55, 2003.

[10] R. Kelly, Ed., "Smart Classroom", Campus Technology, vol. 20, pp. 10, 2006.
[11] A. Atabekov, "Internet of Things-based Smart Classroom Environment: Student Research Abstract", in Proceedings of the 31st Annual ACM Symposium on Applied Computing, April 2016.

[12] L. R. Winer and J. Cooperstock, "The "Intelligent Classroom": Changing Teaching and Learning with an Evolving Technological Environment", Computers \& Education, vol. 38, pp. 253-266, 2002. 